\title{
Ensino Religioso e a gestão educacional: uma análise a partir da ética complexa de Edgar Morin
}

\author{
Religious Teaching and educational management: an analysis \\ from the complex ethical of Edgar Morin
}

\section{Célia Smarjassi}

Doutora em Ciências da Religião, doutoranda em Educação Escolar, professora da Faculdade Adventista de Hortolândia (UNASP/HT), São Paulo, SP - Brasil, e-mail: celsmarjassi@hotmail.com

\section{Resumo}

Este trabalho busca desenvolver uma reflexão sobre a gestão do Ensino Religioso na condição pós-moderna na qual a relação com o divino não seja mais pautada pelo medo, pela superstição e, principalmente, pelo fundamentalismo e pela violência, mas pelo princípio ético da solidariedade, do respeito, do reconhecimento mútuo e da tolerância. Elencar desafios impostos à gestão escolar, sobretudo na complexidade do contexto atual, representa um problema ainda maior quando se busca promover um ensino público de qualidade que respeite as diferenças culturais, religiosas e 
individuais dos educandos, sem, contudo, recair numa orientação para valores. Essa meta exige do gestor mais do que competência técnica e política: exige competência humana, responsabilidade social e liderança como serviço. Gerir a disciplina Ensino Religioso em uma escola laica e plural requer do gestor um cuidado especial com as regras de convivência social e democrática, buscando fundamentos, princípios e rumos que norteiem a prática desse componente curricular de modo a alcançar a equidade entre os atores envolvidos dentro da instituição escolar. Com base nos pressupostos da Teoria da Complexidade, nossa reflexão sobre o ER parte de uma perspectiva dialógica de compreensão do ER. O enfoque da ética complexa será priorizado em nossa análise crítica sobre a gestão educacional do ER. A metodologia utilizada baseia-se na pesquisa bibliográfica.

Palavras-chave: Ética. Gestão. Solidariedade. Complexidade. Ensino Religioso.

\section{Abstract}

This paper seeks to develop a reflection about the management of Religious Teaching in the postmodern condition in which a relation with the divine isn't guided by fear, superstition and, mainly, by fundamentalism and violence, but by the ethical principle of solidarity, respect, mutual recognition and tolerance. To list the challenges to school management, especially under the complexity of the current context, represent a problem even greater when one seeks to promote a good public teaching that respects the cultural, religious and individual differences of the learners, not guided by an orientation to values. This goal requires from the manager more than technical and political competence: it requires human competence, social responsibility, leadership as service. Managing the Religious Teaching in a secular and varied school requires from the manager an especial care with democratic sociability rules seeking foundations, principles and directions that guide to the practice of these curriculum components in order to reach equity among the actors involved in the educational institution. Based on the presupposition of the Complexity Theory, our reflection about RT starts from a dialogical perspective of RT understanding. The focus of complex ethics will be prioritized in our critical analysis about the educational management of RT. The methodology adopted here is based on literature research.

Keywords: Measurement. Spirituality. Religiousness. Instruments. 


\section{Introdução}

Uma reflexão a partir da Filosofia, nos dias de hoje, implica trazer um pensamento que se proponha a favorecer a possibilidade de conclamar os homens a dar mais atenção a sua historicidade em vez de se apegar a suas verdades eternizadas e fundamentalistas. Neste trabalho, ensejamos pensar a gestão do Ensino Religioso na condição pós-moderna, na qual a relação com o divino não seja mais pautada pelo medo, pela superstição e, principalmente, pela violência, mas pelo princípio ético da solidariedade, do respeito, do reconhecimento mútuo e da tolerância.

O artigo 19 da Constituição Federal Brasileira qualifica o Estado como laico. Entretanto, prevê no capítulo da Educação, por meio da LDB (Lei n. 9.394/1996), a obrigatoriedade do Ensino Religioso no currículo do Ensino Fundamental, ficando facultativa a presença do aluno (art. 210, $\S 1^{\circ}$ ); delega aos sistemas estaduais e municipais de ensino competência absoluta para dispor sobre os conteúdos e a forma de executar a disciplina ${ }^{1}$.

Para solucionar aspectos contraditórios inerentes da própria Lei, o Executivo assumiu, então, a responsabilidade de alterar o art. 33 da Lei 9.394/1996 por meio de um projeto de lei, originando a Lei n. 9.475/97 (BRASIL, 1997).

A questão do Ensino Religioso no Brasil é tão séria que no dia 5 de agosto de 2010 a Procuradora Deborah Duprat, da Procuradoria Geral da República, propôs uma Ação Direta de Inconstitucionalidade, com pedido de medida cautelar, a fim de que o Supremo Tribunal Federal realize a interpretação conforme a constituição do artigo 33, caput e parágrafos $1^{\circ}$ e $2^{\circ}$ da Lei n. 9.394/1996, para assentar que o ER em escolas públicas só pode ser de natureza não confessional, com a proibição de admissão de professores na qualidade de representantes das confissões religiosas.

Discutir a admissão de professores já nos expõe um primeiro desafio à gestão, pois requer trazer à baila a questão da formação do professor de ER que, de imediato, esbarra em um impasse histórico difícil de ser

1 Cf. JUNQUEIRA; CORRÊA; HOLANDA, 2007. 
superado, uma vez que esse componente curricular originalmente não foi concebido como uma disciplina integrante da Educação. Mediante análise da literatura atual acerca da formação do professor de ER, fica patente uma colcha de retalhos na interpretação e aplicação desse componente curricular, o que denota o grande despreparo profissional para o exercício da disciplina.

O aparente despreparo para se implantar o autêntico ER revela-se, por exemplo, no fato de que os professores que ministram essa disciplina atuam, na maioria das vezes, de forma improvisada nas escolas, que, na falta de um profissional qualificado pedagógica e cientificamente para exercer tal função, acabam solicitando às instituições religiosas um representante mais apto, do ponto de vista teológico, ou oferecem a vaga a professores de outras áreas de ensino que precisam fechar sua carga horária. Nesse sentido, muitas vezes, para estar na moda ou cumprir a legalidade, muda-se apenas a aparência das propostas; no fundo, porém, continua se fazendo a mesma coisa (SANTOMÉ, 1998, p. 10).

Outro desafio repousa no fato de que o ensino no âmbito da educação básica é um fenômeno complexo, e a docência revela-se como uma importante prática social não só porque se concretiza na interação entre professores e alunos, mas também porque "esses atores refletem a cultura e contextos sociais a que pertencem. A intervenção do professor é influenciada pelo modo como pensa e como age nas diversas facetas da sua vida" (SACRISTÁN, 1995, p. 66). O ER não é uma atividade cientificamente neutra, mas recheada de intencionalidade educativa, portanto, importante para a vida ética e social do educando - razão pela qual nos sentimos incitados a não ignorar, nem escamotear essa realidade que se configura, em nossa compreensão, um sério desafio para o gestor educacional.

Diante do exposto, torna-se importante para o gestor repensar, a partir de contextos situacionais, quais são as necessidades formativas dos professores de ER, quais necessidades expõem e quais suscitam mal-estar para o professor de ER, para então pensar em quais critérios se devem basear as ações de formação na atualidade e oferecer atividades formativas para esses docentes.

Continuando a análise, destacamos outro impasse em relação ao ER decorrente da Ação proposta pela Procuradora da República. Houve a 
solicitação para que o Supremo profira decisão de interpretação conforme redação do artigo 11, parágrafo $1^{\circ}$ do Acordo entre a República Federativa do Brasil e a Santa Sé, relativo ao estatuto Jurídico da Igreja Católica do Brasil, aprovado pelo Congresso Nacional e promulgado pelo Presidente da República mediante o Decreto n. 7.107/2010, o qual decreta que o ER em escolas públicas só pode ser de natureza não confessional, ou que seja declarada a inconstitucionalidade do trecho relativo à Católica e a outras confissões religiosas constantes no referido acordo. A procuradora Deborah Duprat postula que o Estado é laico e, portanto, não cabe a ele oferecer ER confessional nas escolas públicas, pois, assim fazendo, estará inculcando nos alunos princípios e valores religiosos partilhados pela maioria. Também assevera pela contratação de professores desvinculados de qualquer tomada de partido e sem a participação de pessoas vinculadas a Igrejas.

Um breve panorama sobre o tema nos mostra que há problemas oriundos das brechas presentes na lei, da contradição explícita na questão de o Estado ser laico e, ao mesmo tempo, oferecer a disciplina Ensino Religioso. Essa disciplina, proposta como tal, impõe desafios ao gestor educacional público. Desse modo, torna-se relevante tecermos algumas palavras sobre a Gestão Educacional na escola pública.

A educação brasileira tem enfocado a gestão do ensino como um conceito ampliado para melhor compreender a complexidade dos problemas educacionais que exigem um olhar ativo e global e, ao mesmo tempo, uma "ação articulada, dinâmica e participativa" (LÜCK, 2011, p. 23). Assim, a gestão educacional é uma área importantíssima da educação que não pode ser negligenciada. Contudo, "aceitando-se que a gestão democrática deve implicar necessariamente a participação da comunidade, parece faltar ainda uma maior precisão do conceito de participação" (PARO, 2010, p. 16).

Tomando como pano de fundo os novos problemas e demandas que a escola enfrenta e às quais ela deve responder, acreditamos ser legítimo incluir no debate um importante desafio relacionado à gestão educacional pública: a presença do ER em uma escola laica e pública, cuja prática em contexto nacional representa um terreno (acidentado) aberto a pesquisas básicas que solicitam muita reflexão e estudo, tendo em vista a 
complexidade que envolve esta área, afeita a múltiplos significados, muitas vezes difíceis de captar, interpretar e traduzir.

A convivência entre as diferentes estruturas religiosas requer um novo modelo de gestão escolar, mais sensível e preparada para ver a floresta como um todo, não apenas árvores isoladas. Requer do gestor (enquanto diretor e/ou professor) liderança, liberando energias e apoiando, orientando e inspirando a convivência social democrática entre os atores dos diferentes segmentos religiosos.

Nesse sentido, é importante trazer à baila outro desafio: "Por sua característica de relação humana, a educação só pode dar-se mediante o processo pedagógico, necessariamente dialógico, não dominador, que garanta a condição de sujeito tanto do educador quanto do educando" (PARO, 2010, p. 108).

O caráter dialógico que deve permear o processo pedagógico no ER nos remete a buscar um referencial teórico que possa trazer alguma iluminação para se pensar questões que, entre outras, necessariamente passa pelo campo da ética. Assim, aproximando-nos mais diretamente do nosso objeto de análise, pode-se dizer que o pensamento complexo defendido por Edgar Morin antecipa temas que vem ao encontro da compreensão quanto à essência da gestão democrática e participativa do ER tão imprescindível à prática do mesmo.

No que se segue, passaremos a levantar os principais conceitos que fundamentam a teoria da complexidade e sua aplicação ao campo da ética, que constituem o liame e o ponto de encontro de sua autoética, antropoética e socioética, postuladas como luz para se pensar a ética que deve permear as religiões em sua diversidade original, o que poderá trazer subsídios para a gestão da disciplina de Ensino Religioso nas escolas públicas sem correr o risco de reduzi-la à transmissão de valores.

\section{A teoria da complexidade de Edgar Morin}

O desenvolvimento do pensamento complexo tem seu ponto de partida quando Morin busca reconduzir o paradigma clássico aos seus limites, resguardando, assim, seu alcance e validade. Portanto, 
para compreender o problema da complexidade é preciso saber primeiro que há um paradigma simplificador. Dessa forma, segundo Morin (2005, p. 59)

[o] paradigma simplificador é um paradigma que põe ordem no universo, expulsa dele a desordem. A ordem se reduz a uma lei, a um princípio. A simplicidade vê o uno, ou o múltiplo, mas não consegue ver que o uno pode ser ao mesmo tempo múltiplo. Ou o princípio da simplicidade separa o que está ligado (disjunção), ou unifica o que é diverso (redução). Nessa vontade de simplificação, o conhecimento científico tinha por missão desvelar a simplicidade escondida por trás da aparente multiplicidade e da aparente desordem dos fenômenos.

Diante da simplificação na explicação dos fenômenos, Morin propõe o paradigma da complexidade. Mas antes é preciso tecer algumas considerações sobre complexidade, já que essa ideia foi tratada de modo superficial e, por isso, suscita alguns mal entendidos.

Segundo Morin, o primeiro mal entendido refere-se à concepção da complexidade como resposta (simplista), quando na realidade é preciso entendê-la como desafio e inspiração para pensar. Também não pode a complexidade ser considerada inimiga da ordem e da clareza.

$\mathrm{O}$ segundo mal entendido refere-se a atribuir à complexidade o aspecto de completude, pois a complexidade aponta para o contrário: para a incompletude do conhecimento. Para Morin, "[n]um sentido, o pensamento mutilante se desfaz, excluindo o que eu chamo de simplificadores e por isso ele luta, não contra a incompletude, mas contra a mutilação" (MORIN, 2010, p. 176). Nesse sentido, a complexidade persegue um conhecimento multidimensional, respeitando as diversas dimensões desse conhecimento. Em outras palavras, a complexidade apresenta-se como dificuldade, como incerteza, e não como clareza e resposta.

Alcançar a complexidade suplanta qualquer definição prévia, pois existem complexidades e não apenas uma complexidade. Para tanto, Morin recorre a diferentes caminhos, "avenidas", que conduzem ao desafio da complexidade. Esse desafio percorre caminhos organizados por ordem e desordem. 
A desordem traz em si dois polos: objetivo e subjetivo - daí seu aspecto de incerteza. Já a organização é movida por alguns princípios básicos: o princípio do holograma, da organização recursiva e o principio da dialógica. Desse modo, o pensamento complexo se utiliza do conceito básico de "sistema auto-organizado complexo" que remete à ideia chave de unitas multiplex. Trocando em miúdos, a organização, como o primeiro passo do sistema da complexidade, consiste em associar em si mesma as ideias de unidade e de multiplicidade que, num primeiro momento, repelem-se e se excluem.

Para chegar a essa compreensão, Morin percorre diferentes avenidas.

A primeira avenida é a da irredutibilidade do acaso e da desordem, que nasceram no universo das ciências físicas com a irrupção do calor, que é a agitação-colisão-dispersão dos átomos ou moléculas, e depois com a irrupção das indeterminações microfísicas, e, enfim, na explosão originária e na dispersão atual do cosmo. Tudo o que se pode dizer é que a desordem e o acaso estão presentes e ativos no universo, entretanto, envoltos por incerteza, inclusive no que diz respeito à natureza da incerteza que o acaso nos traz.

A segunda avenida da complexidade contempla a transgressão, nas ciências naturais, dos limites daquilo que poderíamos chamar de abstração universalista que elimina a singularidade, a localidade e a temporalidade. Em outras palavras, não se pode trocar o singular e o local pelo universal. É preciso uni-los.

A terceira avenida diz respeito à complicação, pois os fenômenos biológicos e sociais apresentam infinitas interações. Daí, segundo Morin, a pertinência do paradoxo levantado por Niels Bohr que diz: "[a]s interações que mantêm vivo o organismo de um cachorro são impossíveis de ser estudadas in vivo. Para estudá-las corretamente, seria preciso matar o cão" (MORIN, 2010, p. 179).

A quarta avenida aborda uma misteriosa relação complementar, e logicamente antagônica entre as noções de ordem, de desordem e de organização. Essa relação pressupõe que os fenômenos (organizados) podem surgir de uma agitação ou de uma turbulência desordenada. 
A quinta avenida da complexidade é a da organização. A organização resulta de um sistema composto por diferentes elementos, revelando uma unidade e uma multiplicidade. Para Morin, aqui surge uma dificuldade lógica: "a organização é aquilo que constitui um sistema a partir de elementos diferentes; portanto, ela constitui, ao mesmo tempo, uma unidade e uma multiplicidade. A complexidade lógica de unitas multiplex nos pede para não transformarmos o múltiplo em um, nem o um em múltiplo" (MORIN, 2010, p. 180).

Atrelado a isso, é importante sublinhar que, simultaneamente, um sistema é mais e menos do que aquilo que poderíamos chamar de soma de suas partes. Porém, concomitantemente,

o todo organizado é alguma coisa a mais do que a soma das partes, porque faz surgir qualidades que não existiriam nessa organização; essas qualidades são "emergentes", ou seja, podem ser constatadas empiricamente, sem ser dedutíveis logicamente; essas qualidades emergentes retroagem ao nível das partes e podem estimulá-las a exprimir suas potencialidades (MORIN, 2010, p. 180).

A exemplo disso, podemos evocar o quanto o homem (ser individual) carrega e expressa a cultura, a linguagem, a educação do todo social ao qual pertence.

Nesse contexto, adentramos na sexta avenida quando Morin ressalta a introdução de um elemento surpreendente: o princípio hologramático. Conforme define o autor, "holograma é a imagem física cujas qualidades de relevo, de cor e de presença são devidas ao fato de cada um dos seus pontos incluírem quase toda a informação do conjunto que ele representa" (MORIN, 2010, p. 181).

Para a elucidação desse princípio, Morin evoca o pensamento de Pascal: "Só posso compreender um todo se conheço, especificamente, as partes, mas só posso compreender as partes se conhecer o todo" (PASCAL apud MORIN, 2010, p. 181-182). Com base nessa premissa, é oportuno apontar que a explicação linear cede espaço para um tipo de explicação dinâmica, circular. Como corolário, todo fenômeno implica num movimento que vai das partes para o todo e do todo para as partes. 
Na esteira do princípio da complexidade, Morin sustenta que se deve unir o princípio hologramático ao princípio de organização recursiva. "A organização recursiva é a organização cujos efeitos e produtos são necessários a sua própria causação e a sua própria produção. É, exatamente, o problema de autoprodução e de auto-organização" (MORIN, 2010, p. 182).

Feitas estas observações, Morin (2010, p. 183) sublinha que

a complexidade não é só um fenômeno empírico (acaso, eventualidades, desordens, complicações, mistura dos fenômenos); a complexidade é, também, um problema conceitual e lógico que confunde as demarcações e as fronteiras bem nítidas dos conceitos como "produtor" e "produto", "causa" e "efeito", "um" e "múltiplo".

Progredindo na compreensão do tema, Morin adentra na sétima avenida para a complexidade, ou seja, a crise de conceitos fechados e claros, recaindo na complementaridade entre os mesmos, ou seja, a crise da clareza e da separação nas explicações. Sob esse prisma, Morin retoma um dos mais profundos debates em torno do paradigma da simplificação - a saber, a ruptura com a grande ideia cartesiana de que a clareza e a distinção das ideias são um sinal de verdade, que não pode haver uma verdade que não seja expressa de modo claro e distinto. $\mathrm{O}$ autor retruca, frisando que "[h]oje em dia, vemos que as verdades aparecem nas ambiguidades e numa aparente confusão" (MORIN, 2010, p. 183).

A questão subjacente a essa discussão aponta para a necessidade de "não isolar um sistema auto-organizado de seu meio: é preciso unir intimamente auto-organização e eco-organização" (MORIN, 2010, p. 184).

Desse modo, torna-se imperativo adentrar na oitava avenida da complexidade, que é a volta do observador presente em sua observação. Isso requer a erradicação de vez da ilusão da possibilidade de eliminar o observador nas ciências sociais. A visão complexa pressupõe um retorno à modéstia intelectual, assim como a volta a uma aspiração autêntica da verdade. Resulta disso o princípio da reintegração do conceptor na concepção. Nas palavras de Morin, "A teoria, qualquer que seja ela e do que quer que trate, deve explicar o que torna possível a produção da própria teoria e, se ela não pode explicar, deve saber que o problema permanece" (MORIN, 2010, p. 186, grifo do autor). 
Nesse caso, assume uma situação de relevo o problema da contradição, pois a ciência progride tanto em razão do que ela tem de científico, como também em razão do que ela tem de não científico. A contradição indica o erro. Por isso, para Morin, a observação de Bohr é imprescindível quando diz que é "preciso aceitar a contradição entre as duas noções que se tornaram complementares, já que, racionalmente, as experiências levavam a essa contradição. Daí chega-se ao complexus do complexus, a essa espécie de núcleo da complexidade onde as complexidades se encontram" (MORIN, 2010, p. 188).

Num primeiro olhar, tudo parece desafio, obstáculo. Ao avançarmos pelas avenidas da complexidade, deparamos com dois núcleos ligados. O núcleo empírico que contempla, de um lado, desordens e eventualidades e, de outro lado, as confusões, complicações, multiplicações proliferantes. Já o núcleo lógico, também formado por dois lados, de um lado compreende as contradições que devemos enfrentar e, de outro lado, as indecidibilidades próprias da lógica.

Frente a tudo isso, torna-se imperativo traçar o caminho de um pensamento multidimensional lógico que agrupe e promova a formalização e a quantificação, mas que não se limite a isso. Finalmente, o apelo para o pensamento multidimensional reclama a busca pelo caminho de um pensamento dialógico.

Segundo a expressão que pedimos de empréstimo a Morin, "o termo dialógico quer dizer que duas lógicas, dois princípios, estão unidos sem que a dualidade se perca nessa unidade" (MORIN, 2010, p. 189). Para alguns casos, deriva do conceito de dialógica a ideia de "unidualidade", por exemplo, o homem é um ser unidual, pois é simultaneamente biológico e cultural.

Prosseguindo a discussão sobre a dialogia da presença simultânea de complementaridade e antagonismos, Morin sustenta que a ciência se fundamenta na dialógica entre imaginação e verificação, empirismo e realismo. Dito isso, nosso autor defende ainda que a ciência se desenvolveu graças a uma dialógica complexa permanente, complementar e antagônica - antagonismos que funcionam como estimuladores e reguladores. Morin acrescenta ainda que é preciso unir o princípio dialógico ao princípio hologramático que, por sua vez, está ligado ao princípio recursivo. 
Diante disso, segundo o pensador

o desafio da complexidade nos faz renunciar para sempre ao mito da elucidação total do universo, mas nos encoraja a prosseguir na aventura do conhecimento que é o diálogo com o universo. O dialogo com o universo é a própria racionalidade (MORIN, 2010, p. 190-191).

Por isso a complexidade evoca a estratégia para avançar no incerto e no aleatório. Isso explica por que a complexidade dispensa metodologia. Todavia, não prescinde de um método. Nesse sentido, para Morin, o imperativo da complexidade é um uso estratégico do que chama de dialógico, de pensar de forma organizacional.

O percurso pelas avenidas da complexidade postula outros olhares para compreender mais claramente o pensamento complexo. Essa será nossa tarefa nas próximas linhas.

Para entendermos o pensamento complexo em Edgar Morin, é necessário explicitar, em primeiro lugar, os conceitos de ordem e desordem. Entretanto, isso implica, segundo Morin (2010, p. 197),

conceber um quarto e novo olhar, dirigido para nosso olhar, como muito bem disse Heins von Foerster. Temos de olhar para o modo como o concebemos a ordem e para nós mesmos olhando para o mundo, isto é, incluir-nos em nossa visão de mundo.

O conceito de ordem, por sua riqueza e diversificadas formas, ultrapassa as ideias de estabilidade, rigidez, repetição e regularidade concebidos pelo antigo determinismo, que conceituava a ordem pelo viés da lei anônima, impessoal e suprema regente do universo, lei que, por isso, consagrava-se como a verdade ímpar desse universo.

$\mathrm{Na}$ visão complexa, o conceito de ordem suplanta o conceito de lei, mostrando que a ordem se complexificou de várias formas e não pode ser concebida como anônima e geral, pois está vinculada a singularidades o que equivale a dizer que sua própria universalidade é singular como o universo é singular. 
Decorre dessa tese o fato de que a ordem está ligada à ideia de interações, o que chama a existência de uma estrutura. Em relação a isso é preciso notar que, com a noção de estrutura, a ideia de ordem solicita a de organização. Como assevera Morin:

Na verdade, a ordem singular de um sistema pode ser concebida como a estrutura que o organiza. De fato, a ideia de sistema é a outra face da ideia de organização. Creio, portanto, que a ideia de estrutura está a meio caminho entre as ideias de ordem e de organização. A organização, entretanto, não pode ser reduzida à ordem, embora a comporte e produza (MORIN, 2010, p. 198, grifo do autor).

Em outras palavras, as organizações produzem ordem, que por sua vez são coproduzidas por princípios de organização. A ideia ampliada de ordem reconhece a ideia de organização; para tanto, reclama o diálogo com a ideia de desordem. Isso porque recorre e depende das ideias de interação e de organização, enriquecendo-se. Mas é preciso ressaltar que, ao enriquecer-se, o conceito de ordem relativizou-se. Complexificação e relativização caminham unidas. Daí a afirmação de que não existe ordem absoluta, incondicional, eterna em nenhum plano.

Se a ordem não prescinde recursivamente da desordem que extrapola o conceito de acaso que a comporta, a desordem é mais rica que a ordem, pois contempla um polo objetivo e um polo subjetivo.

No polo objetivo, a desordem representa as agitações, dispersões, colisões, irregularidades e as instabilidades, os desvios que surgem num processo, as desorganizações e as desintegrações. Em outras palavras, a desordem significa os ruídos, os erros. Também o polo subjetivo incluiria desordem do espírito e se expressa pela incerteza.

A desordem é um macroconceito que comporta a aleatoriedade. Nas palavras do autor:

A desordem coopera na geração da ordem organizacional; ao mesmo tempo, presente na origem das organizações, ameaça-as incessantemente com a desintegração, ameaça que tanto vem do externo (acidente destrutivo) quanto do interno (aumento da entropia). Acrescento que a auto-organização, característica dos fenômenos vivos, comporta permanente 
processo de desorganização transformando em processo permanente de reorganização, até a morte final, evidentemente (MORIN, 2010, p. 200).

A concepção de desordem solicita não apenas a concepção de organização, mas em muitas situações a de ambiente. Mas vale ressaltar que a incerteza que a aleatoriedade carrega é bastante enriquecedora. Certo é que não se pode insistir na miséria da ordem ou da desordem solitária, pois um mundo simplesmente determinista e um mundo simplesmente aleatório excluem por completo, um e outro, o espírito humano que observa o que é necessário e tenta buscar colocação em algum lugar.

É imprescindível ligar esses dois mundos que se excluem se quisermos conceber o nosso mundo. Como observa Morin,

Há certamente contradição lógica na associação ordem e desordem, mas menos absurda do que a débil cisão de um universo que seria apenas ordem ou que estaria apenas entregue ao deus acaso. Digamos que ordem e desordem isoladas são metafísicas; juntas, são físicas. Portanto, temos de aprender a pensar conjuntamente ordem e desordem (MORIN, 2010, p. 203).

Para trabalhar com o acaso é preciso recorrer à estratégia e tomar ciência de que a ordem é relativa e relacional e que a desordem é incerta. Mais que isso, ordem e desordem podem compor os dois lados de um mesmo fenômeno; por exemplo, "uma explosão de estrelas é fisicamente determinada e obedece às leis da ordem físico-química, mas, ao mesmo tempo, constitui deflagração, desintegração, agitação e dispersão; por conseguinte, desordem" (MORIN, 2010, p. 203).

Daí a necessidade de promover uma dialógica entre organização e ambiente, objeto e sujeito para reconhecer o campo real do conhecimento. Ora, o conhecimento resulta de nossa visão de mundo, logo, não é pura.

Ainda, é preciso grifar que o trabalho com a incerteza incita o pensamento complexo, pois mostra que nunca haverá uma fórmula mágica que dirija o universo. A complexidade pressupõe pensar o uno e o múltiplo juntos, o certo e o incerto, o lógico e o contraditório e não se esquecer de incluir o observador na observação. O olhar do observador, por mais que queira, não é de todo imparcial. Daí a necessidade de ser 
vigiado por princípios éticos. A ética complexa ocupará nossa atenção nas próximas linhas.

\section{A ética complexa: autoética-socioética-antropoética}

Para Morin é imprescindível "considerar uma ética sem outro fundamento que ela mesma. Quero dizer, não podemos encontrar uma justificação filosófica transcendente que permitiria integrar a ética em si mesma" (PENA-VEGA; ALMEIDA; PETRAGLIA, 2011, p. 40).

Contudo, esse tipo de ética também carrega em seu bojo problemas de três ordens: o primeiro recai nas contradições éticas, isto é, no confronto de imperativos antagônicos; o segundo repousa no plano das incertezas éticas; o terceiro assenta-se à problemática do "eu" em relação a si mesmo. O imperativo ético presente a qualquer momento poderá se deparar com a necessidade de se fazer escolhas, que muitas vezes envolvem riscos, gerando o problema das contradições éticas. É sobre esse pano de fundo que se deve recolocar a ética, ou seja, numa perspectiva da complexidade.

Nas palavras do autor, "a ética se manifesta em nós de uma maneira imperativa, como exigência moral” (MORIN, 2007, p. 19). Essa carga ética tem sua gênese no interior do indivíduo e se lhe apresenta como um dever. Também emana de uma fonte externa por meio da cultura, das crenças, das normas de uma comunidade, que constituem regras coletivas. Além dessas fontes, acrescente-se uma fonte anterior, originária da organização viva repassada geneticamente. Essas três fontes são interligadas ao modo de um rizoma.

Nesse sentido, a ética complexa de Edgar Morin envolve três movimentos interdependentes alicerçados na tríade indivíduo-sociedade-espécie: a autoética, a socioética e a antropoética.

A arquitetura desses tópicos baseia-se no cruzamento destes três eixos, e constitui três percursos diferentes de leitura que respondem pela ideia de ética complexa. É no centro dessa tríade complexa que emerge a consciência e o espírito humano, como afirma Morin: 
Indivíduo-sociedade-espécie não são apenas inseparáveis, mas coprodutores um do outro. Cada um destes termos é ao mesmo tempo meio e fim dos outros [...]. No seio desta tríade complexa emerge a consciência e nosso espírito propriamente humano. Esta é a base para ensinar a ética do futuro (MORIN, 2002, p. 113-114).

Como vimos, Morin começa a pensar sobre a ética destacando-a como uma exigência subjetiva que, por sua natureza, comporta vários elementos. O primeiro refere-se à religação ética claramente delineada em sua fala: "Todo olhar sobre a ética deve perceber que o ato moral é um ato individual de religação com o outro, religação com uma comunidade, religação com uma sociedade e, no limite, religação com a espécie humana" (MORIN, 2007, p. 21).

Este ponto da reflexão induz nosso pensador a abordar a questão da modernidade ética com seus grandes deslocamentos e rupturas na relação indivíduo-sociedade-espécie. Com a secularização da sociedade, o peso do imperativo religioso da ética é suplantado pelo próprio culto que a nação moderna requer e impõe em períodos de paz, vigorando apenas quando a pátria corre perigo. A era planetária advinda dos tempos modernos reclama, a partir do humanismo laico, uma ética metacomunitária para todos. Nela acondicionam-se elementos da ética universalizada de Kant, porém, mostra-se insuficiente para Morin.

Assim, a autoética de Morin apresenta-se como possibilidade de uma ética do futuro por agregar o aspecto da responsabilidade, que, como já declarara Hans Jonas, o aspecto responsabilidade fora negligenciado inúmeras vezes no tema da ética.

Segundo Morin é possível levantar outra questão em que se abre um dos mais profundos debates em nossa sociedade, isto é, a questão da crise dos fundamentos da ética no mundo ocidental, em que se percebe cada vez mais a ausência de Deus e a dessacralização da lei. A crise dos fundamentos da ética faz parte da crise geral dos fundamentos da certeza, do conhecimento filosófico, do conhecimento científico.

Por isso, a principal reivindicação do autor para se pensar a crise ética contemporânea é, simultaneamente, a crise da religação da tríade já mencionada, que leva em sua entranha um anseio de reconciliação. 
O pensador prossegue defendendo que importa refundar a ética; regenerar as suas fontes de responsabilidade-solidariedade significa, concomitantemente, regenerar o circuito de religação indivíduo-espécie-sociedade na e pela regeneração de cada uma dessas instâncias.

Essa regeneração pode partir do despertar interior da consciência moral, do surgimento de uma fé ou de esperança proveniente de uma crise, de um sofrimento, de um amor e, hoje, do chamado vazio ético e de sua deterioração ética. Essas questões represadas na crise dos fundamentos não solicitam um novo fundamento para a ética, mas, sim, novas fontes, novas energias para regenerá-la no circuito de religação, um retorno às origens, ou seja, às fontes cósmicas.

Esse é o motivo por que o autor propõe a ética complexa, isto é, a ética da religação, cuja missão é religar: religar aos nossos, aos outros e à Terra Pátria. A ética complexa pressupõe que essa religação só possa ocorrer mediante a fraternidade e no amor. Segundo Morin, "a ética complexa é simultaneamente una e múltipla. Unifica no seu tronco comum autoética, socioética, antropoética. Nessa unidade/pluralidade, a ética complexa ordena que assumamos eticamente a condição humana" (MORIN, 2007, p. 195).

Diante dos argumentos expostos, podemos inferir que a ética complexa repousa sobre a ambiguidade e a contradição, além de comportar a aposta e a estratégia. Daí seu caráter de incerteza quanto aos resultados. Outro ingrediente que a torna complexa é o fato de ser uma ética da compreensão que, por sua vez, reconhece e respeita a complexidade humana em todas suas nuances.

Diante disso é possível concluir que a ética complexa é frágil, pois é uma ética da aposta e reclama por inúmeras reformas. Complexa, essa ética se assenta na dialógica em que racionalidade, amor e poesia estão em permanente dinâmica e nunca se dá por acabada, concluída. Daí seu objetivo de se regenerar continuamente para não se reduzir à moralina. Busca regenerar o humanismo em duas perspectivas: o humanismo ético de respeito mútuo universal e o humanismo antropocêntrico. O humanismo regenerado acredita na possibilidade da metamorfose das sociedades rumo a uma Terra Pátria. Por isso, a ética complexa fundamenta-se na esperança ligada à desesperança. Conforme declara Morin: "a esperança do possível é gerada sobre o impossível” (MORIN, 2007, p. 199). 
Queiroz (2008, p. 37) põe em relevo

[u]m item especial das conclusões que aparecem ao final da obra. Refere-se à tarefa de resistência. Resistir é a atitude que possibilita unir compaixão e compreensão no enfrentamento à crueldade do mundo, da vida, da sociedade é a barbárie humana, principais fontes das crises que atravessamos.

Resumindo, a ética complexa apresenta-se como uma ética de resistência à crueldade do mundo e à barbárie humana, impelindo o homem à tolerância, a compaixão, à mansidão e à responsabilidade. Assim, viver humanamente é assumir plenamente as três dimensões da identidade humana: a identidade individual (autoética), a identidade social (socioética) e a identidade antropológica (espécie), resistindo a qualquer coisa que tente impedir a plenitude desse viver por meio da fé ética, que é o amor. Para tanto, é preciso assumir a responsabilidade pelo futuro do homem.

\section{A aplicação do pensamento ético moriniano ao ER}

Como anunciado neste trabalho, uma reflexão sobre aspectos éticos na gestão do ER a partir do pensamento de Edgar Morin é o nosso tema central. Considerada a condição em que se encontram os debates atuais sobre o ER no Brasil, buscamos abrir uma análise dos desafios impostos a esse componente curricular a partir de uma discussão da ética e de sua articulação com a gestão educacional, objetivando alcançar princípios e rumos que possam colaborar no sentido de viabilizar uma convivência democrática e solidária. Revisitando a História da Educação no Brasil, observamos que a história do ER, especialmente de seu retorno à grade curricular em 1996, tem sido escrita por meio de uma linguagem de conflito e contradições. Por isso, a gestão da disciplina Ensino Religioso em uma sociedade laica e plural requer a compreensão de quão complexa é a sociedade.

Esse cenário de conflitos e contradições revela-se desafiador para todos os atores envolvidos e solicitados a aceitar compreender o diferente. Assumir comportamentos e valores de modo a contribuir para que 
se crie um ambiente harmônico e de respeito às crenças, solidarizar-se com posturas religiosas silenciadas seja por ignorância de quem medeia as relações, seja por métodos autoritários impostos pela força da maioria hegemônica. Isso acirra a questão de como, no interior de uma mesma instituição de ensino repleta de diferenças culturais e religiosas, é possível gerir a disciplina ER, direcionada por um objetivo pedagógico comum: o fenômeno religioso.

Em conformidade com essas necessidades, a intuição fundamental de nossa reflexão consiste em trazer à tona aquilo que é de particular interesse para nós: mostrar as possibilidades que o pensamento complexo aplicado à ética poderá oferecer-nos enquanto sustentáculo teórico para pensar a gestão do ER num momento em que o homem parece ter perdido seus parâmetros éticos, a ponto de deixar a humanidade universal em situação de risco, sobretudo porque a humanidade encontra-se fragmentada, desorientada, desestabilizada. Pensar o ER nesse contexto não é tarefa fácil.

O tema da complexidade pressupõe uma relação dialógica, em que o todo e a parte têm o mesmo valor, em que o indivíduo não pode ser compreendido separado da espécie e da sociedade, que, em última instância, compõem o planeta, afinal, complexo quer dizer "tecido juntos". Assim sendo, cada um de nós carrega a identidade terrestre, planetária. Nesse sentido, nenhuma religião, cultura, posição social poderá ser maior que a identidade terrestre impregnada em cada sujeito. Portanto, não há de prevalecer minorias ou maioria religiosa, mas o ser humano, o outro de mim mesmo.

A ética complexa, em seus pilares autoética, sócioética e antropoética, pode nos inspirar a reflexão, a motivação para repensar a possibilidade de viver a pluralidade das confissões na própria confissão de fé, além de inspirar os homens a se reconhecerem mais como seres portadores da mesma identidade terrestre, ainda que distantes pelas multifaces da pluralidade religiosa e cultural peculiar ao mundo contemporâneo e pós-moderno.

Essa ética caracterizada pela solidariedade, pelo respeito, pela responsabilidade e pelo reconhecimento mútuo da condição humana não se alcançaria por meio de lição de moral; portanto, não estamos pregando o 
ER apenas como transmissor de valores. "Ela deve ser formada nos espíritos a partir da consciência de que o humano é ao mesmo tempo indivíduo, parte de uma sociedade, parte de uma espécie" (MORIN, 2007, p. 20). Não podemos negar essa tripla concepção.

Entretanto, Morin lamenta: “[o]ra a educação para a compreensão está ausente dos nossos ensinos" (MORIN, 2007, p. 19). O reconhecimento mútuo de que a compreensão mútua entre os humanos, tanto próximos como estranhos, é imprescindível para a superação do escândalo da incompreensão que permeia as relações humanas. Cientes dessa realidade e necessidade, Morin acredita que ensinar a compreensão "constituiria uma das bases mais seguras da educação para a paz, à qual estamos associados por essência e vocação" (MORIN, 2007, p. 20). Sob essa perspectiva, cabe aos gestores educacionais, por meio do ER, privilegiar a educação para a compreensão e aceitação da diversidade religiosa como algo natural no mundo complexo.

Entendemos que, num mundo onde muitas religiões expressam a falta de amor, a limitação, o descaso e o desrespeito com outras expressões religiosas, explicitando uma total falta de respeito com aqueles que não partilham a mesma fé, a ética complexa de Edgar Morin apresenta-nos uma inspiração para o exercício de fecundas reflexões na atualidade, sobretudo para que possamos compreender que a identidade e a humanidade se revelam numa práxis que supera fronteiras étnicas, culturais, religiosas, sociais, econômicas, no intuito de congregar e integrar olhares e ouvidos despidos de qualquer tipo de preconceito.

Desse modo, acreditamos que a ética complexa de Morin poderá auxiliar-nos na reflexão filosófica do ER, de modo a defendermos a integração harmônica entre o indivíduo, a espécie e a sociedade, entre católicos, protestantes, cristãos, judeus, islâmicos, budistas - enfim, entre eu, o outro e o planeta como partes imprescindíveis à beleza do caleidoscópio. Desse modo, a questão do ER não pode ficar à margem das discussões acadêmicas, tampouco da agenda do gestor escolar. Enfim, a ética complexa pode nos levar a refletir sobre a dialógica na relação indivíduo-espécie-sociedade, de modo fazer prevalecer o respeito mútuo e a luta pelo reconhecimento e os estados de paz. 


\section{Conclusão}

Ao propor uma reflexão abordando os desafios que o ER impõe à gestão educacional não tivemos a pretensão de promover uma compreensão ampla e definitiva do assunto, tendo em vista que o debate sobre esse componente curricular permanece aberto à discussão, práxis imprescindível na vigência de modelo aberto de construção de conhecimento inerente da democracia que deve contemplar a escola. Objetivamos, sim, levantar algumas questões para a reflexão no campo da gestão educacional sobre as diferentes "organizações" do ER nos sistemas de ensino, a fim de motivar a reflexão sobre práticas pedagógicas de ER, no intuito de repensar os significados das ações realizadas à luz da legislação vigente.

Chamou-nos a atenção o fato de, após busca bibliográfica a respeito dos desafios impostos à gestão escolar, não termos encontrado (até o momento) nada que abordasse o tema do ER como desafio à gestão. Assim, considerando a ausência de reflexão sobre o tema, podemos inferir que a orientação do assunto não é percebida de modo a considerar a mudança paradigmática que deve reger esse componente curricular, mas é muitas vezes norteada por um antigo e perigoso modelo, explicitando uma compreensão limitada do ER, gerando ineficiência e ineficácia por inclinarem para o distanciamento e para a ignorância das diferenças religiosas, sobretudo das minorias.

Talvez mereça um estudo mais aprofundado a investigação da consciência (concepções, crenças e práticas) que os gestores têm sobre a questão do ER e qual seu papel em relação a assegurar a efetivação plena e democrática desse componente curricular.

Almejamos identificar duas dimensões que coexistem quando se fala em ER, ainda que em nossa busca não conseguíssemos detectá-las: a dimensão do ER e a dimensão da Gestão Escolar como parte e todo do sistema educacional. Essa visão hologramática de Educação nos encaminhou para trazer ao debate uma reflexão sobre a ética moriniana a fim de motivar um olhar para o ER como parte e todo do sistema educacional, portanto, como mais um desafio a ser enfrentado pelo gestor comprometido com a educação integral do aluno. 
Em conclusão, ainda que provisória, podemos dizer, como Antônio Machado, que "é ao andar que se faz o caminho". Do mesmo modo, a gestão educacional democrática só se faz fazendo, ou seja, diante de tantos impasses em torno do modo como gerir o ER, não podemos nos acomodar: é preciso construir o caminho do ER, mesmo entre acertos e erros, e, como a "ética da resistência", não podemos parar o trabalho de pesquisa, de luta, de defesa pelo reconhecimento, crescimento e plena realização da disciplina que nos leva a crer que todos são tecidos juntos fazemos parte da mesma espécie, carregamos a mesma identidade. Daí, enquanto indivíduos, devemos desenvolver e praticar a autoética que "é, antes de tudo, uma ética de si para si que desemboca naturalmente numa ética para o outro" (MORIN, 2007, p. 93). Desse modo, acreditamos em que na gestão do ER a ética seja sua parte vital e assuma fins éticos como prioridade nos seus projetos pedagógicos. Nesse sentido, é mister assumir uma postura ética e olhar para o ER de modo a enxergar e enfrentar os desafios que lhes são inerentes em vez de ignorá-lo. Para isso pareceu-nos bastante oportuno o estudo da ética da complexidade de Morin, que nos conclama para olharmos com a mesma atenção e respeito o todo e a parte. Finalizando, deixamos o caminho de nossa reflexão sobre a gestão democrática participativa do ER em aberto, pois é possível e preciso recomeçar a viagem sempre, ainda que seja necessário abrir novo caminho caminhado.

\section{Referências}

BRASIL. Lei n. 9.475, de 22 de julho de 1997. Dá nova redação ao art. 33 da Lei n. 9.394, de 20 de dezembro de 1996, que estabelece as diretrizes e bases da educação nacional: Diário Oficial da União, Poder Legislativo, Brasília, DF, 23 jul. 1997. Seção 1, p. 15824.

LÜCK, H. Concepções e processos democráticos de gestão educacional. 7. ed. Petrópolis: Vozes, 2011.

JUNQUEIRA, S. R. A.; CORRÊA, R. L. T., HOLANDA, A. M. R. Ensino Religioso: aspectos legal e curricular. São Paulo: Paulinas, 2007. 
MORIN, E. 0 método 3: o conhecimento do conhecimento. 3. ed. Porto Alegre: Sulina, 2005.

MORIN, E. O método 6: ética. Porto Alegre: Sulina, 2007.

MORIN, E. Ciência com consciência. Trad. Maria D. Alexandre e Maria Alice Sampaio Dória. 14. ed. Rio de Janeiro: Bertrand Brasil, 2010.

PENA-VEGA, A.; ALMEIDA, C. R. S.; PETRAGLIA, I. (Org.). Edgar Morin: ética, cultura e educação. 4. ed. São Paulo: Cortez, 2011.

PARO, V. H. Gestão democrática da escola pública. São Paulo: Ática, 2010.

QUEIROZ, J. J. Pensar a ética em tempos de crise: reflexões colhidas do Método 6 de Edgar Morin. Notadum Libro, n. 11, 2008. Disponível em: <http://www. hottopos.com/notand_lib_11/queiroz.pdf.>. Acesso em: 20 out. 2011.

SACRISTÁN, J. G. Consciência e ação sobre a prática como libertação profissional dos professores. In: NOVOA, A. (Org.). Profissão professor. 2. ed. Porto: Porto Editora, 1995.

SANTOMÉ, J. T. Globalização e interdisciplinaridade: o currículo integrado. Porto Alegre: Artmed, 1998.

Recebido: 06/08/2013

Received: 08/06/2013

Aprovado: 01/10/2013

Approved: 10/01/2013 